\title{
MONITORING VIABLE FUNGAL AND BACTERIAL BIOAEROSOL CONCENTRATIONS TO IDENTIFY ACCEPTABLE LEVELS FOR COMMON INDOOR ENVIRONMENTS
}

\author{
L.D. Robertson \\ Mycotech Biological, Inc \\ Rt. 1 Box 182 \\ Jewett, TX 75846
}

\begin{abstract}
Bioaerosol concentrations between 200 $450 \mathrm{CFU} / \mathrm{m} 3$ have remained largely uncharacterized with respect to potential indoor air quality concerns. This research provides for further description of indoor bioaerosol concentrations and concludes that $\leq 300$ $\mathrm{CFU} / \mathrm{m} 3$ of non-toxigenic or non-pathogenic organisms should be typical for normal, nonimmunocompromised environments. With the exception of Cladosporium, no organism should individually contribute more than $150 \mathrm{CFU} / \mathrm{m} 3$. Furthermore, it is concluded that $>300$ CFU's/m3 and/or not meeting the above criteria should incite some additional level of investigation with respect to; the bias of prominent outdoor bioaerosol(s), adequate filtration, indoor humidity and microhumidity environments, and/or potential indigenous contamination source(s). The author cautions that the $>300 \mathrm{CFU} / \mathrm{m} 3$ threshold is not intended to represent any threshold having medical or health significance and/or necessarily representative of an unacceptable indoor environment. The $>300 \mathrm{CFU} / \mathrm{m} 3$ is intended to be a "reactionary threshold" to incite further investigation as to the cause(s) of what is perceived to be an above average viable concentration for indoor bioaerosols. The author further concludes that outdoor sampling should only be utilized in the relative comparisons to individual indoor components and that indoor/outdoor ratios involving total $\mathrm{CFU} / \mathrm{m} 3$ concentrations should not be utilized as a specific mechanism to evaluate acceptable indoor bioaerosol concentrations.
\end{abstract}

\section{Introduction}

Human exposure to bioaerosols has been documented in a variety of adverse health effects, including allergy, hypersensitivity, respiratory problems, toxicological, and infectious disease ( $\mathrm{I}-13)$. Various fungal and bacterial bioaerosols have been identified and enumerated using several sampling methodologies, yet the specific effects of many airborne microorganisms on human health is not clearly understood. The lack of understanding is in part due to the extreme complexities that exists with respect to sampling methodologies, and bioaerosol data interpretation, as well as, the complexities involving individual human sensitivity. Several methodologies are available to evaluate bioaerosols (14-18); however, there is a current absence of information with regard to the comparability of results. Currently, viable sampling methodologies have been utilized to document fungal and bacterial bioaerosols with respect to indoor environments; however, additional research is necessary in order to develop concentration standards involving exposure, in general.

The purpose of this research was to evaluate viable bioaerosol concentrations to aid in the development of guidelines for the interpretation of indoor fungal and bacterial bioaerosols. The specific objectives of this study were to determine the total concentrations of indoor bioaerosols in a variety of indoor environments in the United States and to specifically characterize individual bioaerosol components with respect to population and concentration.

\section{Materials and Methods}

This research evaluated a total of 1116 bioaerosol samples collected over a nine (9) month period from eighteen (18) states. Nine hundred and thirty four (934) of the samples were collected from indoor commercial and residential environments equipped with forced heating, ventilating, and air conditioning systems. The remaining 182 samples were collected from the outdoor environment in those same geographical areas. Bioaerosol samples were collected with an Andersen N-6 single stage microbial sampler and the Andersen 10-850 two stage microbial sampler. Data obtained from the first stage of the Andersen 10-850 was excluded from the sample population. All samplers were calibrated at a flow rate of 28.3 liters per minute. Indoor sampling times ranged from 2 to 5 minutes which provided detection limits ranging between 18 and 7 colony forming units (CFU) per cubic meter (m3), respectively. Outdoor sampling ranged from 1 to 3 minutes which provided detection limits ranging between 35 and 12 
CFU's/m3, respectively. Collection was made on sterile $100 \mathrm{~mm} \times 15 \mathrm{~mm}$ polystyrene petri plates containing 30 milliliters of $2 \%$ malt extract agar $(19,20)$. All samples were sent to Mycotech Biological, Inc., by 1-3 day courier services for further processing. Immediately upon arrival, collections were incubated at $25^{\circ} \mathrm{C}$ with 12 hour light-dark cycles. Isolates were examined 7 days after incubation. Morphological structures of filamentous fungi were characterized utilizing standard light microscopic technique (22-25). Mature sporulating fungal colonies were identified to genus and enumerated as $\mathrm{CFU} / \mathrm{m} 3$. Yeast, bacteria, Actinomycetes and sterile hyphae were reported as yeast, bacteria, Actinomycetes and sterile hyphae CFU's/m3, respectively. Data obtained from these collections was not adjusted relative to the positive hole conversion.

\section{Results}

The evaluation of 934 indoor samples indicated fungal and bacterial bioaerosols that ranged from $0 \mathrm{CFU} / \mathrm{m} 3$ to $6077 \mathrm{CFU} / \mathrm{m} 3$. This sample set demonstrated an average of 157 CFU $/ \mathrm{m} 3$. Eighty seven (87) percent of the sample set indicated indoor concentrations below $300 \mathrm{CFU} / \mathrm{m} 3$. Seven (7) percent of the samples ranged between $300-500 \mathrm{CFU} / \mathrm{m} 3$ and six (6) percent were over $500 \mathrm{CFU} / \mathrm{m} 3$. The number of individual bioaerosols per sample range from 0 to 10 with an overall average of 4 bioaerosols observed per sample.

Thirty seven (37) genera of fungi were identified from indoor bioaerosol samples. Unspecified groups of yeast, sterile hyphae, bacteria, Actinomycetes, and unidentified Hyphomyces were also observed. Seven (7) of the forty two (42) total bioaerosol components were distinguished with respect to the frequency of occurrence. These included Cladosporium, yeast, sterile hyphae, Penicillium, Aspergillus, Alternaria, and Curvularia. Cladosporium was recovered from $77 \%$ of the indoor sample set and averaged $92 \mathrm{CFU} / \mathrm{m} 3$. Yeast and sterile hyphae were both observed in $56 \%$ of the sample set; however, yeast averaged $52 \mathrm{CFU} / \mathrm{m} 3$ while sterile hyphae averaged $29 \mathrm{CFU} / \mathrm{m} 3$.

Penicillium was observed in 50\% if the indoor samples and averaged $48 \mathrm{CFU} / \mathrm{m} 3$. Aspergillus was documented to occur in $33 \%$ of the indoor samples and demonstrated an average airborne concentration of $20 \mathrm{CFU} / \mathrm{m} 3$. Alternaria occurred in $17 \%$ of the samples and averaged 30 $\mathrm{CFU} / \mathrm{m} 3$. Curvularia was observed in $7 \%$ of the samples and demonstrated an average of 20 $\mathrm{CFU} / \mathrm{m} 3$. The remaining 34 components were observed in $3 \%$ or less of the total sampling population. Despite relatively low frequency of occurrence, several of these incidents, when present, indicated a moderate contribution to bioaerosol concentration. These incidents included; Geotrichum, Fusarium, Drechslera, Nigrospora, Monocillium, Cunninghamella, Trichoderma, Humicola, and Pithomyces.

The evaluation of 182 outdoor samples indicated fungal and bacterial bioaerosols that ranged from $0 \mathrm{CFU} / \mathrm{m} 3$ to $12668 \mathrm{CFU} / \mathrm{m} 3$. This sample set demonstrated an average of 860 $\mathrm{CFU} / \mathrm{m} 3$. Thirty three (33) percent of the sample set indicated outdoor concentrations below $300 \mathrm{CFU} / \mathrm{m} 3$. Sixteen (16) percent of the samples ranged between $300-500 \mathrm{CFU} / \mathrm{m} 3$ and fifty one (51) percent were over $500 \mathrm{CFU} / \mathrm{m} 3$.

Thirty three (33) genera of fungi were identified from outdoor bioaerosol samples. Unspecified groups of yeast, sterile hyphae, bacteria and Actinomycetes were also observed. Fourteen (14) of the thirty seven (37) total bioaerosol components observed were distinguished with respect to frequency of occurrence. These included Cladosporium, sterile hyphae yeast, Penicillium, bacteria, Alternaria, Aspergillus, Geotrichum, Curvularia, Fusarium, Epicoccum, Drechslera, Acremonium, and Phoma. The remaining twenty three (23) components were observed in $4 \%$ or less of the total sampling population. Despite relatively low frequency of occurrence, most of these incidents, when present, indicated a moderate to substantial contribution to bioaerosol concentration.

\section{Conclusions}

The data obtained from this study indicates that indoor average of $158 \mathrm{CFU} / \mathrm{m} 3$ is 5.5 times less, or eighteen percent $(18 \%)$ the of average outdoor concentration of $860 \mathrm{CFU} / \mathrm{m} 3$. This data is consistent with other studies involving the comparison of indoor and outdoor concentrations (26). The indoor average of 158 $\mathrm{CFU} / \mathrm{m} 3$ is similar to indoor concentrations observed in other research $(27,28)$. The eighteen percent $(18 \%)$ value obtained in this study falls below the thirty three percent $(33 \%)$ indoor/outdoor ratio recommended for indoor environments established by the American Conference of Governmental Industrial Hygienists (20). However, the data observed in this research indicates that outdoor bioaerosol fluctuation introduces an inherent problem with respect to utilizing indoor/outdoor ratios as a mechanism to establish recommendations for 
indoor exposure. Considerable variation has been documented to occur in outdoor bioaerosol concentrations $(29,30)$. Ten percent $(10 \%)$ of the total outdoor samples evaluated by this research indicated outdoor concentrations less than 100 $\mathrm{CFU} / \mathrm{m} 3$, with two (2) samples indicating 0 $\mathrm{CFU} / \mathrm{m} 3$. The application of the $33 \%$ indoor/outdoor ratio to a $100 \mathrm{CFU} / \mathrm{m} 3$ outdoor concentration would establish $33 \mathrm{CFU} / \mathrm{m} 3$ as a recommended indoor concentration; however, only $27 \%$ of the indoor sample collected in this investigation indicated concentrations less than $33 \mathrm{CFU} / \mathrm{m} 3$. This data indicates that the application of the $33 \%$ indoor/outdoor ratio, when applied to below average or low outdoor concentrations, results in a recommended indoor concentrations which does not reflect the typical indoor data observed in in this study; and furthermore, may be to extreme with respect to providing acceptable concentration limits for indoor environments. Additionally, the application of the $33 \%$ indoor/outdoor ratio to $12668 \mathrm{CFU} / \mathrm{m} 3$, which was the highest outdoor bioaerosol concentration observed by this study, would establish a concentration of $4180 \mathrm{CFU} / \mathrm{m} 3$ as a recommended indoor concentration level. However, only $0.1 \%$ of the indoor environments observed indicated indoor concentrations in excess of $4180 \mathrm{CFU} / \mathrm{m} 3$. This data indicates that the application of the $33 \%$ indoor/outdoor ratio, when applied to above average or high outdoor concentrations, results in a recommended indoor concentration which does not reflect the typical indoor data observed in in this study, and furthermore, may be to liberal with respect to providing acceptable concentration limits for indoor environments. The author suggests that such numerical extremes would potentially exist with respect to any value selected as an indoor/outdoor ratio. Therefore, total indoor/outdoor CFU/m3 comparisons should, in general, be avoided as a basis for evaluating and recommending exposure levels for indoor bioaerosols.

The specific comparison of individual indoor and outdoor components may be of some benefit in evaluating the potential risk for exposure. Literature is of record that indicates that indoor bioaerosols should not be significantly different that outdoor bioaerosols (30). Of the total 45 bioaerosol incidents recovered in this study, twenty percent $(20 \%)$ were found exclusively indoors. Although present, these bioaerosols occurred in three percent $(3 \%)$ or less of the indoor sampling population and may be of little concern with respect to establishing general guidelines.
Further investigation is necessary to determine if the recovery of these organisms has some specific relationship with indoor environments in general. Seven percent $(7 \%)$ of the incidents were found exclusively outdoors. Thirty three (33) of the total forty five (45) bioaerosol components observed were common to both indoor and outdoor samples. Of this sample set, ninety four percent (94\%) of the average CFU $/ \mathrm{m} 3$ were in greater concentration outdoor when compared to indoor. Individual outdoor components ranged from 3 to 71 percent higher in average CFU/m3 with respect to indoor components, respectively. This data is consistent with referenced literature indicating indoor and outdoor populations should be similar, with indoor concentrations being lower than outdoor concentrations for individual organisms. This study indicated Pithomyces and Humicola were found in a greater indoor concentration when compared with outdoors. Further investigation is necessary to determine if the recovery of these organisms has some specific relationship with indoor environments in general.

The data obtained from this study indicates that concentrations $\leq 200 \mathrm{CFU} / \mathrm{m} 3$ may be considered typical for indoor bioaerosols and supports other conclusions involving research on indoor bioaerosols $(27,28)$. Miller, et. al., has suggested that indoor airborne samples should contain less than $300 \mathrm{CFU} / \mathrm{m} 3$ of common fungi (e.g. Cladosporium) and less than $150 \mathrm{CFU} / \mathrm{m} 3$ of all other mixed species other than pathogenic or toxigenic species (32). This statement would suggest that 450 CFU's/m3 would be a maximum recommended value for indoor environments. This value represents 2.9 times the average of 158 observed in this study and 2.25 times the value of 200 $\mathrm{CFU} / \mathrm{m} 3$ suggested by $Y$ ang, et.al. as acceptable indoor concentrations. Holt and Reponen, in separate investigations have sited $500 \mathrm{CFU} / \mathrm{m} 3$, or 3.2 times the average indoor $\mathrm{CFU} / \mathrm{m} 3$ value observed in this study as representative of abnormal indoor fungal sources $(30,33)$.

Evidence is of record that generally identifies bioaerosol concentrations that are considered typical and/or abnormal with respect to indoor environments. Values of less than 200 $\mathrm{CFU} / \mathrm{m} 3$ have been identified as acceptable for normal environments while values of 450-500 $\mathrm{CFU} / \mathrm{m} 3$ have been utilized to support the presence of various unacceptable indoor air quality situations. The data gained from this research, in conjunction with other bioaerosol research, provides for the basis of further 
characterization of indoor bioaerosol concentrations between 200 and $450 \mathrm{CFU}$ 's/m3. The author supports the following recommendations for non-adjusted indoor bioaerosol concentrations:

1. $\leq 300 \mathrm{CFU} / \mathrm{m} 3$ of non-toxigenic or nonpathogenic organisms should be typical for normal, non-immunocompromised environments because $87 \%$ of the sample population indicated less than $\leq 300 \mathrm{CFU} / \mathrm{m} 3$. With the exception of Cladosporium, no organism should individually contribute more than $150 \mathrm{CFU} / \mathrm{m} 3$.

2. $>300 \mathrm{CFU} ' \mathrm{~s} / \mathrm{m} 3 \mathrm{and} /$ or not meeting the above criteria should incite some additional level of investigation with respect to; the bias of prominent outdoor bioaerosol(s), adequate filtration, indoor humidity and microhumidity environments, and/or potential indigenous contamination source(s).

The author cautions on the indiscriminate use of any bioaerosol data and/or recommendations. As with any sampling methodology, false negatives and false positive may occur, as well as diurnal, seasonal or transient variation. Given these factors, the above recommendations are suggested only as general guidelines with respect to interpreting general bioaerosol data. The $>300 \mathrm{CFU} / \mathrm{m} 3$ threshold is not intended to represent any threshold having medical or health significance and/or necessarily representative of an unacceptable indoor environment. The $>300$ $\mathrm{CFU} / \mathrm{m} 3$ is intended to be a "reactionary threshold" to incite further investigation as to the cause(s) of what is perceived to be an above average viable concentration for indoor bioaerosols. The author further suggests that outdoor sampling should only be utilized in the relative comparisons to individual indoor components and that indoor/outdoor ratios involving total $\mathrm{CFU} / \mathrm{m} 3$ concentrations should not be utilized as a specific mechanism to evaluate acceptable indoor bioaerosol concentrations.

More research is needed to further evaluate and characterize acceptable indoor bioaerosol concentrations and populations. These areas include detailed geographical and seasonal influences, toxigenic and pathogenic organisms, specific yeast and bacteria

bioaerosols, as well as investigations into nontypical, immuno-compromised and/or medical environments. New sampling methodologies are being developed to evaluate bioaerosol concentrations. These include ergosterol, beta Beta 1-3 Glucan, DNA fingerprinting, and others. While these methodologies may offer alternative means to evaluate bioaerosols in the future, the practical use of these technologies is not currently in place. As with all sampling methodologies, certainly these new methodologies will have benefits as well as shortcomings. However, at the present, viable bioaerosol recovery does provide an investigator with a readily available means to evaluate bioaerosols. Despite all the associated variables associated with this methodology, viable bioaerosol sampling offers the clearest avenue of data comparability to current bioaerosol references. This investigation has further contributed to this growing volume of bioaerosol reference and has provided the additional interpretive information with respect to current field investigations.

\section{References}

1. Burge, Harriet, Pope, Andrew $M$, and Patterson, Roy, Committee on the Health Effects of indoor Allergens, Division of Health Promotion and Disease Prevention, Institue of Medicine, Indoor Allergens, National Academy Press, Washington, D.C. 1993, ISBN: 0-30904831-1.

2. Davidsohn, Israel, John Bernard Henry. Clinical Diagnosis by Laboratory Methods. 15th Edition, W.B. Saunders Company, ISBN: 07216-2922-9

3. Davis, Benard D. , Dulbecco, Renato., Eisen, Herman N., Ginsberg, Harold S., Wood, Jr., Barry W, Principles of Microbiology and Immunology Harper \& Row, Publishers, New York, New York, 1968, Library of Congress Catalog Card Number: 68-24153.

4. Ganong, William F. Review of Medical Physiology. Lange Medical Publications, Los Altos, California, USA, 6th Edition, ISBN: 087041-132-2,

5. Hansen, Shirley J. "Managing Indoor Air Quality", The Fairmont Press, Inc., Lilburn, GA, USA, 1991.

6. Jensen, Marcus M., Donald N Wright,Microbiology for the Health Sciences, Prentice Hall Inc., Englewood Cliffs, New Jersey, USA., ISBN: 0-13-487364-6. 
7. Kwon-Chung, K.J. , John E. Bennett,Medical Mycology, Lea and Febiger, Philadelphia, PA, USA ISBN : 0-8121-1463-9

8. Larone, Davise H., Medically Important Fungi, A Guide to Identification, Third Edition, ASM Press, Washington, D.C., USA, ISBN : 1-55581-091-8

9. O'Leary, William. Practical Handbook of Microbiology,, CRC Press Inc., 1989, ISBN: 08493-3704-6.

10. Pope,Andrew M., Roy Patterson, Harriet Burge, "Indoor Allergens", National Academy Press, Washington, D.C, 1993.

11. Walsh, Phillip J., Dudney, Charles, S., Copenhaver, Emily D., Indoor Air Quality, CRC Press Inc., Boca Raton, FL, USA. 1989, ISBN: 0-8493-5015-8.

12. Wilson, J. Walter .,The Fungous Diseases of Man, University of Califomia Press, Berkelely, California, USA., 1974, ISBN: 0520-01344-1.

13. Brief, R.S., and T. Bernath. 1988. Indoor Pollution: Guidelines for prevention and control of microbiological respiratory hazards associated with air conditioning and ventilation systems. Applied Industrial Hygiene. Vol.3: pp.5-10.

14. Burge, Harriet, Bioaerosols, CRC Press, Boca Raton, Florida, USA., 1995, ISBN 087371-724-4

15. Cox, Christopher S, and Christopher M. Wathes. Bioaerosols Handbook, CRC Press, Boca Raton, Florida, USA., 1995, ISBN: 187371-615

16. Robertson, L.D. $1995 . \quad$ Minimizing Microbial Contamination: Indoor Air Quality Methods and Practices. Plant Technology \& Safety Management Series / No. 3: p. 23-30.

17. Morey,Phillip R. , James C. Feeley,Sr., and James A Otten. Biological Contaminants in Indoor Environments. American Society for Testing and Materials. STP 1701. 1990.

18. Etkin, Dagmar Schmidt. 1994. Biocontaminants in Indoor Environments. Cutter Information Corp., Arlington, MA, USA., ISBN: 0-943779-87-1
19. Atlas, Ronald $\mathrm{M}$. Handbook of Microbiological Media. CRC Press, Inc., Boca Raton, Florida, USA., ISBN: 0-8493-2944-2.

20. ACGIH, "Guideline for the Assessment of Bioaerosols in the Indoor Environment", American Conference of Govemmental Industrial Hygienists, Cincinnati, Ohio. 1989.

21. Jensen, Marcus M., Donald N. Wright, Microbiology for the Health Sciences, Prentice Hall Inc., Englewood Cliffs, New Jersey, USA., ISBN: 0-13-487364-6.

22. Alexopoulos, Constantine John. Introductory Mycology. John Wiley \& Sons, Inc., New York, New York, USA., ISBN: 0471-02213-6.

23. Kindrick, Bryce. The Fifth Kingdom. Mycologue Publication, Waterloo, Ontarios, Canada, 1985, ISBN: 0-9692237-0-6.

24. Barnett, H.L., and Barry B. Hunter, Illustrated Genera of Imperfect Fungi, Burgess Publishing Company, Minneapolis, Minnesota, USA., 1972, ISBN: 8087-0266-1

25. Smith, Grant E.,Sampling and Identifying Allergenic Pollens and Molds, Blewstone Press, San Antonio, Texas, USA., 1984, ISBN: 0930961-00-5.

26. Morey, P.R., and B.A. Jenkins. ASHRAE/SOEH Conference IAQ'89: The Human Equation: Health and Comfort. 1989, pp. 67-71.

27. Yang, C.S., L-L. Hung, F.A. Lewis, and F.A. Zampiello. 1993. Airborne fungal populations in non-residential building in the United States. Indoor Air'93 International Conference. Vol 4:pp. 219-224

28. Toth, C. 1992. Microbials in the overall context of indoor air quality investigation. Proceedings of the First Annual IAQ Conference and Exposition. pp. 255-259.

29. Pasanen, A.L., T. Reponen, P Kallioski, and A. Nevalainen. 1990. Seasonal variation of fungal spore levels in indoor and outdoor air in the subarctic climate. Proceedings of Indoor Air '90: 5th Intemational Conference on Indoor Air Quality and Climate. Vol. 2: pp. 39-46.

30. Reponen, T.,A. Nevalainen, M. Jantunen, M. Pellikka, and P. Kalliokoski. 1990. 
Proposal for an upper limit of the normal range of indoor air bacteria and fungal spores in subarctic climate. Proceedings of Indoor Air "90: 5th International Conference on Indoor Air Quality and Climate. Vol. 2: pp. 47-50.

31. Reynolds, S.J., A.J. Streifel, and C.E. McJilton. 1990. Elevated airborne concentrations of fungi in residential and office environments. American Industrial Hygiene Association Journal. Vol 51: pp. 601-604.

32. Miller, J.D., A.M. LaFlamme, Y. Sobol, P. Lafontaine, and R. Greenhalgh. 1988. Fungi and fungal products in some Canadian houses. International Biodeterioration. Vol. 24: pp. 103120

33. Holt, G.L. 1993. Determination of Seasonal Indoor/Outdoor Fungal Ratios and Indoor Bacterial Levels in Non-Complaint Office Buildings. Ph.D. Thesis, Department of Environmental Health Sciences, School of Public Health, University of Alabama, Birmingham, Alabama, USA. 